\title{
Turismo para cegos: velhos e novos simbolismos numa obra literária sobre a cegueira
}

Manoela Cristina Correia Carvalho da Silva ${ }^{1}$ Alessandra Santana Soares e Barros ${ }^{2}$ Miralva dos Santos Silva ${ }^{3}$

O cego adivinho, o cego mendigo, o cego prodígio cujos sentidos remanescentes em muito compensam a perda da visão, o cego que supera obstáculos e torna-se exemplo em livros de autoajuda: esses são apenas alguns exemplos da diversidade de representações da cegueira na literatura. Em Turismo para cegos, romance de Tércia Montenegro, somos apresentados a mais um dos inúmeros personagens cegos presentes em obras literárias. Laila, a protagonista da história, é uma mulher que gradativamente perde a visão. Mas como esse texto contemporâneo trabalha a questão da deficiência visual? A obra é inovadora ou repete antigos estereótipos? De que modo a protagonista se relaciona com a própria cegueira e com os demais personagens videntes? O presente texto se propõe a responder a essas questões.

Inicialmente, apresentaremos a cosmovisão ocidental acerca do fenômeno da deficiência visual e apontamos os estereótipos mais comuns associados a personagens cegos em obras literárias a fim de analisarmos Turismo para Cegos a partir dessas informações. Em seguida, introduziremos as ideias de Goffman acerca do conceito de estigma e revisitamos a obra Turismo para cegos à luz das ideias deste teórico.

\section{A cegueira na literatura}

Para melhor entender a cosmovisão ocidental acerca do fenômeno da deficiência visual, podemos nos valer da obra E se eu fosse cego?, de Bruno Sena Martins (2006). Na primeira parte do livro, o autor analisa os valores legados pelas culturas greco-romana e judaico-cristã como

\footnotetext{
${ }^{1}$ Doutoranda em educação e professora adjunta da Universidade Federal da Bahia (UFBA), Salvador, BA, Brasil. Dorcid.org/0000-0002-9613-6783. E-mail: penteacher2@yahoo.com.br

${ }^{2}$ Doutora em antropologia e professora associada da Universidade Federal da Bahia (UFBA), Salvador, BA, Brasil.D orcid.org/0000-0003-3347-6323.E-mail: alssb@ufba.br

${ }^{3}$ Dout oranda em educação e professora assistente da Universidade do Estado da Bahia (Uneb), Salvador, BA, Brasil.D orcid.org/0000-0003-1089-4696. E-mail: miralvaj@yahoo.com.br
} 
estando na raiz dos sentimentos de ambiguidade diante da cegueira que até hoje permeiam a cultura ocidental e alimentam a representação da cegueira na literatura.

Gregos e romanos cultivavam sentimentos contraditórios em relação à cegueira. Ao mesmo tempo que encaravam a deficiência visual como um castigo divino e a associavam à perda da luz (uma espécie de morte), a importância da oralidade em sua cultura garantia a possibilidade de participação ativa de cegos na vida intelectual e política da comunidade. Isso explica o prestígio de uma figura como Homero, o poeta cego autor dos épicos Ilíada e Odisseia, assim como o mito do cego vidente personificado em Tirésias, o adivinho de Édipo Rei. A ideia, que ainda hoje alimenta o imaginário ocidental, é a de que, por não poderem enxergar a luz terrena, os cegos estariam em contato mais direto com o universo espiritual e o mundo das ideias, o que lhes conferiria sabedoria e o poder de ver o futuro.

Ainda segundo Martins (2006), esse mesmo caráter contraditório em relação à cegueira pode ser encontrado na tradição judaico-cristã. Por um lado, a análise do texto bíblico evidencia a existência de leis que incentivavam uma atitude de cuidado com as pessoas com deficiência; por outro, fica claro que era negada a essas pessoas a participação ativa no culto a Deus, já que eram impedidas de exercer serviço sacerdotal e de se aproximar do altar. A deficiência estava associada à impureza e ao pecado, mas deveria inspirar sentimentos de compaixão e caridade nos mais afortunados. Aí está a raiz da atitude de assistencialismo e da associação da cegueira à vulnerabilidade, piedade e dependência.

Para completar o quadro traçado por Martins (2006) e tentar detectar os estereótipos mais comuns associados a personagens cegos em obras literárias, podemos lançar mão de obras como as de Jacob Twersky (1955), Deborah Stein (1990) e Adrian Spratt (2015). Estes autores se dedicaram a traçar panoramas acerca da representação da cegueira na literatura ocidental e têm em comum o diferencial de serem eles mesmos pessoas com deficiência visual e de se debruçarem exclusivamente sobre o fenômeno da cegueira física, e não da cegueira metafórica, especialmente em obras originalmente publicadas em língua inglesa.

O primeiro desses autores, o americano Jacob Twersky, inicia seu relato chamando a atenção para dois importantes fatores que governam a representação da cegueira na literatura: i) a tendência a enxergar os cegos como uma classe de pessoas à parte, dotada de características 
estereotipadas e homogêneas, independentemente de se tratarem de pessoas com deficiência congênita ou adquirida, ou de qualquer outro fator; e ii) o fascínio pela figura do cego, cuja presença em obras literárias é absolutamente desproporcional se comparada ao número de pessoas com deficiência visual que efetivamente compõem a população mundial.

Twersky (1955) divide sua obra em quatro grandes capítulos que englobam desde as primeiras menções a cegos encontradas no Velho Testamento até textos publicados no ano de 1955. Segundo o autor, ao longo desse período, é possível notar uma pequena mudança em relação à forma como os personagens cegos são trabalhados. A partir de 1873, por exemplo, ao se descrever algum personagem cego como indefeso ou dependente, frequentemente lhe é atribuída alguma outra deficiência além da cegueira, numa possível demonstração de que a deficiência visual não seria mais entendida como causa suficiente por si só para justificar o desamparo de um personagem.

Entretanto, a análise empreendida pelo autor demonstra que os personagens cegos são geralmente apresentados como vítimas da punição divina e descritos como seres profundamente infelizes e dignos de pena, de modo que a cegueira se torna um castigo pior que a própria morte. Muitas vezes, esses personagens são descritos como imorais, cruéis e malignos ou, num outro extremo, como virtuosos, puros e angelicais com base apenas em sua própria cegueira. Além disso, o autor apresenta vários exemplos de personagens femininos cujo sonho do matrimônio é negado pelo fato de serem cegas, demonstrando a aparente dificuldade de conciliação entre sexualidade e cegueira.

Deborah Stein (1990) é outra autora a traçar um grande panorama acerca da figura do cego na literatura. Aliando os escritos do próprio Twersky (1955), de Kirtley (1975) e de Monbeck (1973) à sua análise pessoal de obras publicadas entre meados da década de 1960 e final da década de 1980, ela evidencia a permanência de antigos estereótipos e o surgimento de novas tendências na representação da cegueira.

Ao iniciar seu relato, Stein (1990) apresenta as características elencadas por Monbeck (1973) como sendo aquelas mais frequentemente atribuídas a personagens cegos ao longo da história. Para Monbeck, via de regra, os cegos são apresentados como pessoas mal ajustadas, infelizes, impotentes, imprestáveis, misteriosas, más e dignas de pena que devem ser temidas e evitadas. Além disso, se por um lado, a cegueira é descrita como uma vida relegada a um mundo tenebroso, escuro e associada à punição por 
algum pecado (frequentemente de natureza sexual); por outro, aos cegos são concedidos intuições e poderes sobrenaturais.

Stein, em seguida, complementa a lista apresentada por Monbeck. Para a autora, além das características já apontadas, os cegos normalmente são assexuados ou são impedidos de expressar sua sexualidade devido à deficiência; são amargos quanto a sua condição e, por isso, invejam os videntes; e mesmo quando alegres e bem-ajustados, estão, na realidade, mascarando uma profunda depressão. Ademais, quer sejam descritos como inferiores ou extraordinários, são invariavelmente marginalizados e sua cegueira está sempre em foco, superando qualquer outro aspecto de sua vida. O que mais surpreende a autora, no entanto, é a impressão dada ao leitor de que, independentemente de gênero, idade ou posição social, os cegos formam uma classe homogênea e essas características se aplicariam a todos os cegos de um modo geral, e não a cada personagem em particular; como se entre os cegos não houvesse o mesmo nível de heterogeneidade, nem que eles compartilhassem as mesmas falhas e qualidades inerentes à condição humana.

Após a retomada desses estereótipos mais comuns, que persistem e podem ser encontrados inclusive nas obras mais contemporâneas analisadas por Stein, a autora passa a descrever as mudanças ocorridas a partir das décadas de 1960 e 1970, quando grupos minoritários como negros, mulheres e pessoas com deficiência ganham maior força política e suas histórias de vida alimentam obras de ficção. Segundo a autora, a partir desse período, os personagens cegos são descritos de maneira mais realista e positiva. Além disso, três novas temáticas passam a ser trabalhadas nas obras: a participação mais ativa em sociedade, a independência e a sexualidade. A autora destaca, entretanto, que, quando o assunto é sexualidade, algumas obras acabam caindo na velha armadilha de descrever o cego como imoral ou lhe atribuem proezas sexuais. E, no caso específico dos personagens femininos, a pesar de atraentes e desejáveis, elas são sempre passivas e dependentes, precisando de ajuda e proteção; isso num momento histórico em que as mulheres em geral se tornavam cada vez mais independentes.

O último dos autores selecionados a traçar um panorama sobre a figura do cego na literatura é Adrian Spratt (2015). O diferencial de seu texto é que o autor estende o seu recorte temporal até o ano de 2015 e procura centrar-se na busca por obras escritas por pessoas com deficiência visual. Stein (1990) havia conseguido detectar a existência de 
apenas dois romances para o público adulto escritos por autores cegos com a presença de personagens também cegos. Spratt completa esse quadro citando mais três romances voltados para o público infantojuvenil e uma série de biografias.

Para Spratt, autores videntes, mesmo os mais contemporâneos, tendem a descrever personagens cegos de modo ambíguo e pouco realista; ora retratando-os como excepcionais, ora como dependentes. Por isso, o autor enfatiza a importância de obras escritas por pessoas cegas cujos protagonistas também sejam cegos e cujo tema central das tramas não seja sua própria cegueira. Afinal, a deficiência é apenas um dos diversos aspectos da vida dessas pessoas.

No entanto, em seu panorama, Spratt não encontra obras assim. A maioria dos livros escritos por pessoas com deficiência visual com protagonistas cegos são bastante recentes e trata-se de biografias, que o autor compara aos escritos fantásticos dos grandes exploradores do século XIX. Esses livros são geralmente histórias de superação escritas para satisfazer a curiosidade dos videntes sobre a experiência do "não ver". Spratt critica essa linha editorial e defende o ponto de vista de que a ficção escrita por cegos com protagonistas cegos poderia ter um impacto e valor social muito maiores que essas biografias ou textos infantojuvenis de caráter didático. $\mathrm{O}$ autor defende a ideia de que adotar a estratégia enganosa de conceder superpoderes aos cegos ou descrever histórias de adaptação pouco realistas pode trazer mais consequências negativas que benefícios. Para Spratt, os cegos não precisam ser transformados em heróis, uma vez que já há heroísmo suficiente na vida de qualquer pessoa, seja ela uma pessoa com deficiência ou não.

\section{A representação da pessoa com deficiência visual em Turismo para cegos}

Neste artigo, analisamos Turismo para cegos, romance de estreia da cearense Tércia Montenegro. A autora foi beneficiada com uma Bolsa de Incentivo às Artes da Petrobras em 2013, e o livro foi publicado pela Companhia das Letras em 2015, recebendo o prêmio Machado de Assis de melhor romance, oferecido pela Fundação Biblioteca Nacional. 
A obra, que guarda semelhanças com o livro Sangue no olho, ${ }^{4}$ da chilena Lina Meruane, conta a história de Laila, uma estudante de artes plásticas que gradativamente vai perdendo a visão, em decorrência da retinose pigmentar, e sua relação com Pierre, seu namorado. Narrada pela balconista de um pet shop que vende um pretenso cão-guia ao casal e, posteriormente, envolve-se com Pierre, a história se propõe a apresentar uma protagonista cega que não é nem vítima, nem heroína. A narrativa procura descrever a perda da visão de um modo menos romanceado, desnudando o "luto" e as crises naturais ao processo. Segundo a própria autora, em matéria do jornal Estadão:

A proposta do livro é essa: discutir até que ponto o sofrimento de uma pessoa justifica que ela faça os outros sofrerem. Laila torna-se cruel à medida que sua doença ocular avança. Entretanto, os demais personagens também não são completamente submissos, ninguém é vítima por completo. Não há inocentes (Montenegro apud Sobota, 2015, s.p.).

A escritora também declara ter entrevistado oftalmologistas, conversado com cegos (tendo sido, inclusive, ledora na Sociedade de Assistência aos Cegos em Fortaleza em 2010) e caminhado vendada como parte do laboratório para a construção de Laila. Tudo isso no intuito de simular como a personagem, de fato, agiria (Montenegro apud Maros, 2015, s.p.). Essa decisão da autora de tentar conferir certa verossimilhança a seu texto mesmo tendo direito à licença poética parece ir ao encontro, inclusive, de uma das críticas compartilhadas pelos três autores dos panoramas descritos na seção anterior: a falta de realismo nas descrições de personagens com deficiência visual.

No caso de Turismo para cegos, esse realismo é parcialmente conquistado. Apesar do retrato bem feito da dificuldade de aceitação da cegueira por parte de Laila, problema enfrentado por muitas pessoas com deficiência visual adquirida mais tardiamente, bem como das reações de choque, piedade e curiosidade mórbida dos mais próximos diante de seu diagnóstico, a questão da patologia que acomete Laila poderia ter sido mais bem trabalhada em sua articulação com a trama do romance.

\footnotetext{
${ }^{4}$ Livro de estreia de Meruane no Brasil, San gue no olho narra a história de uma mulher que está lidando com a perspectiva de ficar cega e sua relação com a família e o namorado. Lucina, protagonista do romance chileno, sofrehemorragias oculares por complicações da diabetes. Daí o título do livro.
} 
A escolha da retinose pigmentar como justificativa para a perda gradual da visão por parte da protagonista mostra-se um recurso eficiente. Favorece a ideia da cegueira adquirida como um processo e oferta à narrativa o recurso da dimensão no tempo, já que a retinose causa a degeneração progressiva da retina e, geralmente, é diagnosticada em adolescentes e adultos jovens, como é o caso de Laila.

Entretanto, essa é uma doença hereditária que usualmente acomete mais de um membro de uma mesma família. Se um membro é diagnosticado, recomenda-se fortemente que outros passem por avaliação e aconselhamento genético para planejamento familiar. Contudo, Laila parece ser a única a sofrer com o problema em sua família e, em nenhum momento, outros parentes parecem preocupados com o diagnóstico ou afetados em nível pessoal com a questão. A impressão que se tem é a de que a retinose é um problema particular de Laila e reflexo de sua má sina: "A retinose inspirou nele um misto de piedade e covardia, balbúrdias filosóficas e sessões de revolta - contra si mesmo, contra a moça e o destino" (Montenegro, 2015, p. 10). O corte abrupto da relação de Laila com seus pais e a sua saída de casa para morar com Pierre poderiam, inclusive, ter sido justificados por algum tipo de revolta contra esse caráter hereditário da doença, mas esse aspecto da retinose não é trabalhado.

Além dessa questão, problemas como certas generalizações, ${ }^{5}$ a pretensa perda de lateralidade da protagonista 6 e a suposta estratégia de contagem de passos adotada por Laila, 7 também afetam o realismo da

\footnotetext{
${ }^{5}$ Quem perde a visão tardiamente mantém, principalmente nos primeiros períodos logo que se instala a cegueira, as mesmas reações espontâneas que expressam a resposta do corpo ao choque ou ao sust o, por exemplo. Contudo, o leit or de Turismo para cegos é levado a pensar noutras atitudes reflexas: "Todas as pessoas se agacham quando estão apavoradas, ou se enroscam, se jogam no chão - menos um cego. Um cego se apavora em pé, e é comum esse medo súbito, apesar da bandeira de independência, farfalhante na mão da mídia ou de qualquer um que esteja por fora" (Montenegro, 2015, p. 82).

${ }^{6}$ Uma pessoa cega que perde a visão na idade adulta, e não tem outros comprometimentos associados, permanece com a noção de esquema corporal sem nenhum estranhamento, ao contrário do que o leitor é levado a crer com base em passagens como: "Quando Laila ficou cega, perdeu a noção dos espaços de seu corpo, ou pelo menos passou a estranhá-los, cada membro independente como um ator que se destaca através de um gesto" (Montenegro, 2015, p. 105).

${ }^{7}$ Em geral, pessoas cegas não andam contando passos como Laila: "Mas tudo é cansativo. Um cego não pode relaxar; tem de estar contando passos, percebendo ruídos, de orelhas empinadas como antenas" (Montenegro, 2015, p. 86). Essa estratégia não faz parte de nenhum programa de orientação e mobilidade, pois a passada de uma mesma pessoa pode variar a depender, por exemplo, do seu nível de cansaço e se ela está ou não carregando algum tipo de peso. No entanto,
} 
obra. Contudo, tanto esses aspectos como a própria questão da retinose talvez possam ser explicados pelo ponto de vista adotado pela autora. Como a obra é narrada pela balconista do pet shop, o leitor não tem acesso direto às emoções e pensamentos de Laila. Não há como garantir que o relato da balconista, que não é cega e não tem uma relação próxima com a protagonista (seu relato é basicamente construído a partir do que lhe conta Pierre), seja confiável. A narradora onisciente/intrusa é também uma personagem que, aos poucos, apresenta-se ao leitor como mais que apenas uma balconista: era também uma estudante de jornalismo que ambicionava escrever um livro com base na história de Laila e Pierre. Essas pertenças sobrepostas favorecem, desse modo, os movimentos de construção literária da narrativa e as licenças criativas que lhe cabem quando da elaboração discursiva sobre a experiência da cegueira.

Além disso, a qualidade intrusiva da atitude da narradora do romance está dada não apenas por sua onisciência mas também, no caso específico da história que ela conta, por sua própria e particular curiosidade - quase obsessiva - pelo relacionamento afetivo de um casal incomum: uma mulher cega de temperamento forte e um homem feio e inexpressivo. Logo, o julgamento moral sobre os comportamentos da mulher cega, que chegam ao leitor através dessa narradora, tem de ser apreciado para além das concessões formais que essa estrutura narrativa permite. Como essa narradora acaba se mostrando também uma personagem implicada na trama, como uma mulher que disputa a atenção de um homem, estabelece-se um conflito de interesses entre ela e a cega protagonista, namorada daquele homem. Acentua-se, assim, a parcialidade da perspectiva dessa narradora. Quaisquer deslizes conceituais acerca da realidade clínica da cegueira contidos no texto, bem como qualquer subversão ética na compreensão do papel social do cego, estariam, então, autorizados pelo lugar de fala desse narrador/personagem peculiar.

Nesse sentido, não caberia esperarmos que Turismo para cegos fosse um livro para bem se instruir acerca do treinamento de um cão-guia, para aprender aspectos reabilitativos da orientação e mobilidade ou para compreender as limitações de esquema corporal impostas pelas sequelas da perda de visão. Ademais, é importante pontuar que Turismo para cegos não é essencialmente um livro sobre a cegueira, mas

como Laila não parece ter investido em treinamento de orientação e mobilidade, é possível que a autora tenha articulado logicamente esse comportamento como sendo uma solução nascida da necessidade de deslocamento da personagem. 
uma obra que se utiliza da cegueira como uma estratégia para discutir as relações interpessoais dos personagens.

Para além dessas questões que envolvem o realismo defendido por teóricos como os citados na seção anterior, é interessante notar também como as representações historicamente associadas à cegueira estão colocadas na obra. A autora, graduada em letras, com mestrado em literatura brasileira e doutorado em linguística, dá pistas de que está familiarizada com os modos mais comuns de retratar a cegueira: "Laila afirmava que seria menos inquieta se tivesse boa voz, cantando para se entreter - ou caso tivesse o dom de um profeta, em quem a falta de visão aguçava um tino para o futuro. Ela gostaria de prever os fatos"' (Montenegro, 2015, p. 81).

Contudo, a narrativa parece, em princípio, apresentar caráter ambíguo e contraditório quanto à representação tradicional da deficiência visual na literatura. Ao mesmo tempo em que é possível encontrar uma protagonista extremamente complexa, que chega a gerar inveja em outros personagens, também são veiculados alguns dos mais negativos estereótipos acerca da cegueira. Essa ambiguidade talvez possa novamente estar ligada à questão do foco narrativo adotado. O leitor é levado a se questionar: até que ponto os juízos de valor expressos na obra não seriam reflexo da visão da balconista, uma pessoa comum e que, portanto, estaria apenas expressando preconceitos arraigados no imaginário popular quanto à cegueira?

O relato da dificuldade de Laila em aceitar a própria condição, atitude altamente compreensível numa fase inicial do processo de perda da visão, por exemplo, perpetua-se ao longo da história, assim como a visão da cegueira enquanto escuridão e sofrimento:

"Se tivesse de pintar", ela falou uma vez, "seriam telas pretas, misturando as cores básicas. Aqui e ali deixaria um traço de azul, vermelho ou amarelo - mas no centro concentraria os tons juntos, para criar o preto. Seriam telas desagradáveis, gosmas de tinta acumulada, numa escuridão igual a minha. Se é que o preto nos meus olhos conserva alguma cor, algo primário que resistiu a esse buraco para onde foi o mundo inteiro. Estou como alguém trancado em paredes de ar, ou dentrode um círculo de giz. Parece tão fácil sair e, no entanto, é impossível" - ela dizia isso, e Pierrenãocompreendia nada além do sofrimento (Montenegro, 2015, p. 129). 
A deficiência também é apresentada como doença, porém não uma enfermidade comum, mas algo sério e aterrador: "Era um simples deficiente que sofria de ruína, assim como uns sofrem de cegueira, câncer ou paralisia" (Montenegro, 2015, p. 151). Isso porque a cegueira é, na verdade, quase um tipo de morte: “Na cegueira [...] as coisas não deixam de existir, porém em certa medida elas se subtraem. É um suicídio parcial, como toda mutilação" (Montenegro, 2015, p.70-71). Quemé cego, portanto, perde o encantamento pela vida: "Com a cegueira, perde-se o deslumbramento. A capacidade de se maravilhar depende da visão" (Montenegro, 2015, p.32). O inventário das perdas decorrentes da cegueira apresentado na narrativa é exemplar nesse sentido:

Laila rumina o seu ódio contra esses desconhecidos que recebem o que ela não tem: As cristas no mar prateado. A trama de losangos numa pele envelhecida. Os trilhos do trem. Um milharalàs cinco da tarde. A encruzilhada. O pó sobre os móveis. A estampa do lençol. As árvores e sua geometria de galhos. A cor do pão crocante. As grinaldas. Os vitrais. As marcas no asfalto. Os vultos e os volumes. $\mathrm{O}$ arco de um túnel. As fogueiras. As nuvens. [...] Laila envolve-se com os próprios braços, balançando em desconsolo. O que mais pode perder? Os cartões-postais de qualquer país. Os esportes e as torcidas. As coreografias. Ocirco. O teatro. As fantasias de carnaval. Os filmes pornôs (Montenegro, 2015, p. 46-47).

O inventário deixa transparecer amargura e inveja dos videntes, como já havia pontuado Stein (1990) em seu panorama acerca da cegueira na literatura. Além disso, são retomadas outras características negativas associadas a personagens cegos, ainda que levemente atenuadas por outros pormenores da trama. O episódio do cão-guia, por exemplo, reforça a ideia do quão facilmente Laila pode ser enganada; mesmo que essa ingenuidade seja compartilhada por Pierre, que também é ludibriado. A inatividade da protagonista, conquanto seja resultado de uma escolha calculista da própria Laila, resulta em outros personagens taxando-a de dependente e inválida. Laila, ou a narradora que fala por ela, também é dada a vilanias: "Ela não era heroína, não era exemplar. Não se tornou bondosa por causa da cegueira - e ali, na piscina, ainda desconhecendo o velho demente que virá para poluir a água com células mortas, Laila se exercita" (Montenegro, 2015, p. 42-43). E, por vezes, até a maldades: "Laila devia ter planejado o golpe com antecedência, como quem calcula o momento de atacar logo após uma 
carícia. Ela precisava de um gesto despropositado, um ato desleal que a fizesse sentir-se viva" (Montenegro, 2015, p. 131).

Em contrapartida, contrariando os velhos estereótipos, de modo algum Laila é apresentada como uma personagem assexuada ou passiva: “Então, à noite Laila o buscou por baixo dos lençóis, completamente nua. Conseguiu acariciá-lo de uma forma que o fez esquecer qualquer rancor, colando-se às suas costas com a ponta dos seios duros" (Montenegro, 2015, p. 78). Ela tem plena consciência de seu poder de sedução e o utiliza para benefício próprio, manipulando Pierre a fim de obter dele o que quer para depois abandoná-lo e fugir com Bent:

Desde que se atraiu por uma jovem em perda progressiva de visão, e desde o instante em que resolveu chamá-la para morar em seu apartamento, compensando o esforço de servi-la com a chance de contemplar sua beleza, fingir que ela era uma conquista para um homem como ele, tão feio - desde esse tempo, Pierre já era excessivamente responsável. Laila aproveitava-se disso, recusando tarefas mínimas, para gozar o conforto. Quando queria, ela se tornava bem independente e orgulhosa disso. Mas quase sempre era um fardo nas mãos de Pierre, pesava-lhe numa espécie de preço que ele devia pagar por sua companhia (Montenegro, 2015, p. 91).

Laila é temperamental, por vezes imatura e inconsequente, mas também é invejada por sua ousadia e liberdade. Suas atitudes moralmente reprováveis, contudo, não sãojustificadas exclusivamente por sua cegueira:

Àquela altura, eu estava obcecada pela vida dos dois. O que iniciou como uma espionagem ociosa, feita pela janela do pet shop, dominou meu pensamento - sobretudo em torno de Laila, sua figura incompreensível e poderosa. Parte de suas atitudes seria explicada pela doença, o transtorno de cair num mundo escuro. Mas parte também seria caráter. Laila tinha uma tendência dominante, daquelas que se vênos animais do tipoalfa, conforme repetia Aluísio durante os treinamentos. O território era sempre seu, mesmo que não o enxergasse. Ela fez o namorado gastar com viagens, desfazendo-se de uma coleção de moedas raras; fez um amigo de infância odiá-la, criou impactoem desconhecidos, gritou paralisada na chuva-e, por fim, fugiu na companhia de um pretenso artista que costumava repudiar. Era contraditória e intensa, exatamente como um dia eu quis ser (Montenegro, 2015, p. 137). 
Laila é uma anti-heroína. Entretanto, como previne a própria autora, não há inocentes em Turismo para cegos. Se, por um lado, Laila aproveitase economicamente de Pierre, ele (um homem descrito como fraco e feio) também não perde a oportunidade de desfrutar da relação com uma bela mulher. A busca de autogratificação de Pierre fica ainda mais evidente quando tomamos conhecimento de suas mentiras. A história sobre seu avô andarilho, contada para ganhar a simpatia de Laila e dar início ao seu relacionamento, é uma farsa. Ele também fotografa Laila secretamente e envia essas fotos para sua família sem seu consentimento em troca de dinheiro: "Ela não trabalhava, então nada mais justo que o pai lhe desse uma mesada por vias indiretas. Algo humilhante, mas necessário" (Montenegro, 2015, p. 65).

Esse mesmo tipo de "barganha" pode ser encontrado na relação de Pierre com a narradora, a balconista do pet shop. Depois de ter vendido o falso cão-guia ao casal, ela acaba se tornando a confidente que Pierre precisa para "chorar suas mágoas" após a fuga de Laila. Seu objetivo, contudo, não é altruísta. As confidências de Pierre nada mais são que material para seu primeiro livro: "Eu tinha interesse na história que ele me propôs contar: queria me distrair e, quem sabe, pegar ideias para um personagem. Mas ele não sabia disso e devia me enxergar como alguém delicado, que aceita o café-desabafo por mera cortesia" (Montenegro, 2015, p. 107).

No afã de transformar os relatos que ouve numa boa história, a aspirante a escritora literalmente toma o lugar de Laila e, para tanto, inicia uma relação amorosa com Pierre, pede demissão do emprego e muda-se para seu apartamento. Ainda não satisfeita, ela tenta simular a deficiência da protagonista com auxílio de esparadrapo e óculos escuros, andando pelo apartamento às cegas ou vagando pelas ruas com o auxílio do falso cão-guia. Isso, no entanto, só é possível porque ela descobre as mentiras de Pierre e ele, novamente, deixa-se explorar para ter o benefício de desfrutar da companhia de outra mulher.

A análise da interação entre os personagens torna-se ainda mais rica quando a questão da deficiência e os estereótipos que a acompanham estão em pauta. Como Laila é vista pelos outros personagens? Como ela interage com os videntes no decorrer da história? Por que ela parece não sofrer nenhuma sanção por suas atitudes tão politicamente incorretas? A discussão empreendida por Erving Goffman em sua obra Estigma: notas sobre a manipulação da identidade deteriorada (1988) é particularmente útil na 
busca por essas respostas. Turismo para cegos, como já mencionado anteriormente, é muito mais que um livro sobre a cegueira. É um romance sobre relações pessoais no qual a deficiência tem o efeito de acentuar a dramaticidade inerente aos relacionamentos humanos. Logo, analisá-lo a partir das contribuições de um estudioso da sociologia do desvio como Goffman pode se mostrar uma empreitada frutífera.

Para além dessa justificativa, há ainda outra razão de fundo para uma análise de Turismo para cegos sob a luz da obra de Goffman. No caso de Estigma, o teórico não buscou aspectos da interação cotidiana estabelecida por normais e desviantes no mundo real, no mundo vivido efetivamente. Em vez de realizar observações, entrevistar pessoas, assistir a suas vidas em curso, Goffman preferiu buscar a literatura ficcional ou especializada sobre estigmatizados e, portanto, a qualidade tradutora das realidades experimentadas pelas pessoas contida na literatura. Dessa vez, o campo empírico de Goffman, o grande universo amostral a partir do qual o teórico elegeu seus recortes e, portanto, trouxe-nos seus exemplos, era composto por novelas, biografias, matérias de revistas e de almanaques, além de casos clínicos descritos pela psicologia. Assim sendo, analisar uma obra de ficção como Turismo para cegos à luz da obra de um sociólogo que especificamente se instruiu na literatura, pareceu-nos um caminho produtivo.

\section{Turismo para cegos e a dinâmica dos contatos mistos}

Enquanto representante da microssociologia da Escola de Chicago, Erving Goffman foca no modo como a sociedade ocidental, moderna e urbana, funciona a partir das instâncias menores e quase silenciosas das trocas banais do dia a dia. Interessa especialmente ao teórico a interação estabelecida entre normais e desviantes, e a obra de Goffman que mais claramente nos apresenta esse aspecto é Estigma.

O subtítulo do livro, traduzido para o português como "notas sobre a manipulação da identidade deteriorada", poderia ser reescrito como "notas sobre a manipulação do conflito resultante do não atendimento de expectativas acerca da identidade de uma pessoa". Estigma é um livro que traduz operacionalmente aspectos da dramaturgia social e da sociologia do desvio. Para o interacionismo simbólico, vertente sociológica que instruiu a posição teórica de Goffman, as interações sociais se dão com base em expectativas geradas a partir de pistas 
sugeridas por lugares de pertença de classe, gênero, geração, filiação étnica etc., e são resultado dos mecanismos promovidos pelas várias agências de socialização como, entre outras, a família, a igreja, os aparelhos de Estado e a mídia. Para Goffman, são estigmatizados aqueles indivíduos que não atendem a essas expectativas e estão inabilitados para a aceitação social plena, uma vez que possuem visivelmente ou não - um atributo considerado depreciativo. Para exemplificar condições de desvio em relação à norma, Goffman traz várias categorias de pessoas. Uma dessas categorias propostas pelo teórico é composta por pessoas com deficiência.

Nesse ponto, é importante deixar claro que, embora o livro de Goffman seja por vezes apropriado para fortalecer a argumentação política em defesa dos direitos das pessoas com deficiência, essa não foi a intenção original da obra. Enquanto um empreendimento grandemente antropológico, não há moralidade nas conclusões analíticas a que chega Goffman. Às críticas que eventualmente recebe acerca do caráter individualista e psicologizante de suas reflexões e, nesse sentido, de seu teor inócuo, posto que pouco contributivo a mudanças estruturais, releituras de seu trabalho respondem que:

Existe a acusação de impotência política. É verdade que Goffman não fornece um roteiro para a revolução, nem dá instruções explícitas sobre o tratamento de seus sujeitos de pesquisa. O que é político não se manifesta apenas em plataformas de partido e placas de protesto. [...] podemos considerar uma distinção entre a política e o que é político, a distinção entre partidos, plataformas e eleições e "um índice de um espaço de desacordo". Nesse último sentido, os escritos de Goffman são extremamente políticos: trazendo à tona o que estava escondido (Abrams, 2014, p. 11, tradução nossa).

É fato que a deficiência ocupa grande parte do repertório de exemplos dos quais Goffman lança mão para ilustrar seu pensamento. Contudo, ele assim o fez para favorecer a evidenciação dos mecanismos de interação social na vida cotidiana - seu primeiro e último objetivos. A cegueira, a surdez, a condição de ser cadeirante são de uma qualidade tal que as tornam, nos termos do próprio teórico, bastante intrusivas. Além disso, as deficiências são intrinsecamente provocadoras de movimentos de reorganização de pressupostos e julgamentos sobre o outro, de reordenamentos e renegociações de acordos e termos de 
aceitação mútua. A deficiência inspira questionamentos acerca das habilidades de trânsito social, de felicidade existencial; enfim, de preenchimento de expectativas como uma pessoa inteira. E é exatamente por isso que a deficiência ocupa um papel central na obra de Goffman, especialmente a deficiência visual.

São muito numerosas as referências ao cego em Estigma; algo perfeitamente compreensível numa sociedade visocêntrica como a nossa na qual a deficiência visual possui um caráter fortemente estigmatizante. Em Turismo para cegos, por exemplo, a gradativa perda de visão de Laila traz consigo uma série de respostas negativas não só por parte de familiares e amigos, mas também da própria protagonista. Como o estigma é socialmente construído, o próprio desviante compartilha da cosmovisão dos demais e tem dificuldade para lidar com sua situação:

Desde o diagnóstico, ou até antes (porque não precisou de médico para perceber o que seu corpo avisava), Laila passou a ofender interiormente as pessoas que conhecia, embora nunca chegasse a verbalizar nada. Ninguém escapou, nem ela própria, que se criticou sob várias pers pectivas, convencida de ser medíocre e fracassada. Odiou-se quase tanto quanto os outros, seus parentes, vizinhos ou colegas, indivíduos que eram simples acúmulos de células, sem contribuição para o mundo (Montenegro, 2015, p. 20).

Entretanto, Goffman sempre nos faz lembrar que essa qualidade de discrepância em relação à norma é relativa e que, portanto, aquilo que faz uma pessoa desviante ou estigmatizada em determinado contexto não necessariamente fará em outro. $\mathrm{O}$ atributo considerado depreciativo não tem, em si mesmo, nada de "honroso" nem "desonroso", podendo até mesmo confirmar a "normalidade" de outra pessoa numa situação social diferente. ${ }^{8}$ É interessante, portanto, notar que o caráter negativo da cegueira de Laila e a pretensa superioridade da visão são algumas vezes relativizadas na trama de Turismo para cegos:

Laila também me intrigou: seu modo de abandonar o mundo, desprezando o visível (como fatalmente ocorria), indicava o contrário do meu ponto de localização. Estávamos em extremos, e cheguei a pensar que, apesar da doença, ela era mais livre. Tinha

\footnotetext{
${ }^{8} \mathrm{O}$ conto The country of the blind (Em terra de cego), de Herbert George Wells (1911), é um interessante exemplo de uma narrativa na qual a deficiência visual é a norma e a visão é o atributo estigmatizado.
} 
uma segurança no delírio, uma ânsia que jamais pratiquei porque semprefui barrada pela expressão dos outros, seus rostos e juízos. A rigor, eu podia considerar que esse problema me afetava inclusive em termos profissionais, pois eu trabalhava num pet shop e havia abandonado o curso de jornalismo no meio. Não suportava a imprensa, a venda exagerada de imagens - e somente entre bichos me sentia calma (Montenegro, 2015, p. 122).

Goffman também deixa claro que estigmatizados e normais não se constituem em duas categorias estanques:

[...] o estigma envolve não tanto um conjunto de indivíduos concretos que podem ser divididos em duas pilhas, a de estigmatizados e de normais, quanto um processo social de dois papéis no qual cada indivíduo participa de ambos, pelo menos em algumas conexões e em algumas fases da vida. O normal e o estigmatizado não são pessoas, e sim perspectivas que são geradas em situações sociais (Goffman, 1988, p. 117-118).

Em Turismo para cegos, portanto, Laila se constitui na personagem que mais frequentemente estará desempenhando o papel de estigmatizada. No entanto, características como a feiura de Pierre e o fracasso profissional da balconista também são atributos depreciativos cujo caráter estigmatizante torna a natureza das relações dos personagens muito mais complexa:

Obviamente, Pierre não tinha deficiências físicas, e se alguém assumia a função de escravo no relacionamento era ele, que servia de auxílio ou muleta, dirigindo o carro para Laila, acompanhando os seus gestos para ajudá-la com a pintura, os ambientes desconhecidos, a compra de alimentos e tantas tarefas diárias em que ela se perdia. Jamais, entretanto, Laila parecia agradecida. Ao contrário, às vezes ela o despachava com rispidez, queria que ele fosse embora e reclamava porque sentia quando ele a ficava observando. [...] No íntimo, continuava inseguro, debatendo-se com a consciência da feiura, do aspecto repulsivo de suas mãos suadas (Montenegro, 2015, p. 39).

É justamente a complexidade da interação entre Laila e os demais personagens videntes, um exemplo do que Goffman denomina "contatos mistos", o que torna Turismo para cegos uma obra particularmente interessante. Para Goffman (1988, p. 14), contatos mistos são os momentos nos quais estigmatizados e normais estão na 
mesma situação social, ou seja, "na presença física imediata um do outro, quer durante uma conversa, quer na mera presença simultânea em uma reunião informal". Esses contatos, segundo o teórico, mostram-se especialmente difíceis:

Sugiro, então, que o indivíduo estigmatizado - pelo menos o "visivelmente" estigmatizado - terá motivos es peciais para sentir que as situações sociais mistas provam uma interação angustiada. Assim, deve-se suspeitar que nós, normais, também acharemos essas situações angustiantes. Sentiremos que o indivíduo estigmatizado ou é muito agressivo ou é muito tímido e que, em ambos os casos, está pronto a ler significados não intencionais em nossas ações (Goffman, 1988, p. 18).

Na trama de Montenegro, parte dos conflitos vividos por Laila é resultado dessas "interações angustiadas". O relato das reações de parentes e amigos em face de seu diagnóstico pode exemplificar o quão conflituosos são esses momentos:

A curiosidade mórbida, inerente aos humanos, exercitava-se sobre ela. Laila reduzia-se à condição de um radar, atraindo palpites ou indagações, receitas milagrosas e conselhos. Todos invadiam sua privacidade, examinando seus olhos e rosto como se ela virasse um bicho. Dentre as reações que presenciou, estiveram crises de choro e até dois acessos de riso (de colegas que não a conheciam direito e pensaram que ela fosse uma piadista), porém o mais recorrente e aborrecido eram os discursos infindáveis, circulando primeiro para saber minúcias, esbaldar-se em termos técnicos, informações que Laila confirmava como testemunha direta da doença. Depois, o palavreado vinha como remédio alternativo, ele próprio uma "injeção de otimismo", de acordo com uns tios que passavam mensagens de autoajuda para o endereço eletrônico de Laila (Montenegro, 2015, p. 12).

Segundo Goffman, para que os contatos mistos possam ter sucesso, é necessário entre outras coisas, que o estigmatizado possa desfrutar da aceitação diplomática concedida pelos normais:

Ela depende de que os normais não sejam pressionados além do ponto em que podem facilmente dar aceitação ou, na pior das hipóteses, oferecê-la com dificuldade. Espera-se que os estigmatizados ajam cavalheirescamente e não forcem as circunstâncias; eles não devem testar os limites da aceitação que 
lhes é mostrada, nem fazê-la de base para exigências ainda maiores. A tolerância, é claro, é quase sempre parte de uma barganha (Goffman, 1988, p. 104).

E Laila parecia estar ciente disso:

Quando o viu, ele se encontrava praticamente debaixo do seu nariz, sorrindo com dentões desfocados. Ela piscou repetidas vezes para entender aquele rosto e, a partir daí, cumprimentá-lo com frieza. Ele não percebeu a evasiva; quis ajudá-la com os últimos degraus, segurando-lhe o braço. Ainda que Laila tivesse pensado em desprender-se num puxão, achou que seria grosseiro - outros colegas já tinham feito o mesmo, quando ela descia ou subia escadas, ou queria atravessar a avenida até a parada de ônibus. Ela se calava, fingindo que o gesto era uma cortesia. Em breve, porém, teria real necessidade de ajuda - portanto, melhor não afastar as pessoas, não armar escândalos, sobretudo ali, no meio de gente conhecida (Montenegro, 2015, p. 16-17).

A diplomacia, entretanto, não parece ser o caminho mais usualmente adotado pela protagonista de Turismo para cegos. Laila propositalmente testa limites e vai além, manipulando conscientemente os "ganhos secundários" de sua situação de estigmatizada.

Para Goffman, há contextos nos quais o atributo depreciativo pode funcionar como uma fonte de "ganhos secundários", ou seja, aquilo que poderia ser visto como algo depreciativo pode se tornar um trunfo no momento da "barganha" entre estigmatizados e normais. Isso é o que acontece quando uma pessoa com deficiência, por exemplo, justifica seu insucesso em determinada área com base em sua desvantagem quando, na verdade, o fracasso se deve a outras razões que não a sua deficiência, e exige retratação ou tratamento especial em decorrência disso. Laila habilmente se aproveita dos "ganhos secundários" advindos de sua situação de estigmatizada e usa sua deficiência como desculpa para justificar seus atos e evitar as possíveis sanções advindas de seu comportamento. O episódio do restaurante é particularmente interessante nesse sentido.

Para se retratar com Laila por ter levado seus pais ao apartamento, Pierre resolve levar a namorada para jantar com alguns colegas de trabalho. Laila, ainda ressentida com Pierre, aproveita a situação para arquitetar uma vingança pessoal. Propositalmente, ela 
deixa de alimentar o cão-guia e coloca Pierre e os colegas em situações extremamente embaraçosas:

Pierre permaneceu em pé, segurando firme a guia do cachorro enquanto durou aquele rodízio de apresentações táteis. Notou que Laila parecia demorar perigosamente nos lábios de um dos colegas, o mais jovem, que riu entre o pânico e o desconcerto ao sentir os dedos serpenteando por sua boca e depois pelas orelhas. A esposa dele também hesitava entre raiva e paralisia - afinal, cumprimentos eróticos seriam perdoáveis em cegas que avançam para o marido alheio? Se reclamasse, não iria parecer preconceito? $\mathrm{Na}$ dúvida, ela se conteve, bufando um pouco. Trocou olhares com as demais, que sorriam constrangidas, mas tranquilizadas. Os outros maridos eram muito feios e flácidos para que Laila se demorasse (Montenegro, 2015, p. 95).

O comportamento chocante de Laila passa impune. Os demais personagens, constrangidos diante de sua condição de cega, sentem-se de mãos atadas. E, assim como nesse episódio particular, diversas outras situações na trama acentuam a potencial angústia dos contatos mistos devido ao comportamento propositalmente pouco conciliador de Laila. Acreditamos que essa seja, inclusive, uma das qualidades originais de Turismo para cegos; uma característica que aproxima ainda mais a obra das ideias presentes em Estigma.

Em seu livro, Goffman procura desconstruir a qualidade adaptada supostamente experimentada por uma pessoa com deficiência. Há um investimento muito claro por parte do teórico de tornar desnudos os mecanismos de manipulação dos quais pessoas estigmatizadas, muitas vezes, podem fazer uso e isso nos leva a questionar os pressupostos de desvantagem inexoravelmente imputados a uma pessoa com deficiência. Contudo, é preciso deixar claro que, ao apontar a existência de "ganhos secundários", Goffman não estava emitindo juízos de valor, nem afirmando que a tendência a procurar por elementos que possam ser utilizados como um trunfo numa barganha se restrinja àqueles indivíduos que possuem atributos depreciativos. Essa é uma característica inerente a qualquer ser humano. A inovação introduzida pelo teórico reside no fato de desmistificar a figura do estigmatizado enquanto merecedor de pena e elevá-lo ao status de um ser humano completo, tão passível de falhas quanto qualquer outro. 
Turismo para cegos procura percorrer esse mesmo caminho, brindando o leitor com personagens complexos que, de forma alguma, são inocentes. Não há mocinhos, nem bandidos. Laila não é perfeita, mas representa com maestria a imperfeição do ser humano, seja ele uma pessoa com deficiência ou não.

\section{Considerações finais}

Turismo para cegos é um livro franco - não querendo com isso ser verdadeiro, posto que situado no plano da ficção. Logo, exigir dele aproximações sempre tangíveis com a realidade absoluta da cegueira seria desmerecê-lo em sua originalidade. Se os pesquisadores cegos citados em nosso artigo defendem o realismo, assim o fizeram mais em nome de uma defesa identitária e, portanto, política da cegueira, do que em favor de uma defesa estética da literatura como arte. Ou como filosofia. Nesse sentido, impiedoso na adjetivação da experiência trágica da cegueira, Turismo para cegos é algo niilista. Portanto, do mesmo modo que não se esperam resultados da apropriação política da obra de Goffman que mais se debruçou sobre a deficiência, tanto pela ausência de ancoragens materialistas, quanto pela rudeza com a qual ele revela a realidade mundana do cotidiano das pessoas com deficiência, assim também não deveremos esperar a incorporação fácil do livro de Tércia Montenegro pelo discurso politicamente correto.

Nesse sentido, melhor então que o leitor nunca venha a saber se a cega ali descrita era fato ou fenômeno. Nunca venha a saber o quanto de sua cegueira, de seu sofrimento, de sua perversidade, estavam dados de antemão e o quanto foram criados pela imaginação de uma mulher aspirante à escritora ou simplesmente invejosa. Ou, no mínimo, pela mera ignorância que leva à reprodução do repertório de representações sobre a deficiência compartilhado culturalmente em nossa sociedade e, nesse caso, reproduzido pela narradora. Nesse sentido, eventuais estereótipos no tratamento discursivo da cegueira encontrados na narrativa do livro são perdoáveis e talvez até justificáveis pela estrutura constitutiva da história. Logo, o pouco de caricatura sobre a cegueira, que se alterna à crueza (essa inovadora e corajosa) no tratamento discursivo da inclusão das minorias, encontra no romance Turismo para cegos uma possibilidade não só permitida pela liberdade concedida à 
ficção, como realizada de modo bastante satisfatório pelo manejo das ferramentas literárias por parte da autora.

\section{Referências}

ABRAMS, Thomas (2014). Re-reading Erving Goffman as an emancipatory disability researcher. Disability Studies Quarterly, Toledo, v. 34, n. 1

GOFFMAN, Erving (1988). Estigma: notas sobre a manipulação da identidade deteriorada. Tradução de Mathias Lambert. Rio de Janeiro: LCT.

KIRTLEY, Donald D. (1975). The psychology of blindness. Chicago: Nelson-Hall.

MAROS, Angieli (2015). Tércia Montenegro estreia com romance em que "cega" o leitor. Gazeta do Povo, Literatura, 11 abr. On-line. Disponível em: <https://goo.gl/G2te1T>. Acesso em: 10 maio 2017.

MARTINS, Bruno S. (2006). E se eu fosse cego? Narrativas silenciadas da deficiência. Porto: Afrontamento.

MONBECK, Michael (1973). The meaning of blindness: attitudes toward blind people. Bloomington: Indiana University Press.

MONTENEGRO, Tércia (2015). Turismo para cegos. São Paulo: Companhia das Letras.

SOBOTA, Guilherme (2015). Primeiro romance de Tércia Montenegro discute crueldade e sofrimento. Estadão, Cultura, 16 maio. On-line. Disponível em: <https://goo.gl/eJ87qY>. Acesso em: 10 maio 2017.

SPRATT, Adrian (2015). Time to move past memoir. Site pessoal. On-line. Disponível em: <http://adrianspratt.com/essays/>. Acesso em: 20 set. 2016.

STEIN, Deborah Kent (1990). Shackled imagination: literary illusions about blindness. The braille monitor, v. 33, n. 1, Jan. Disponível em: <https://nfb.org/images/nfb/publications/bm/bm90/brlm9001.htm\#12>. Acesso em: 29 mai. 2017.

TWERSKY, Jacob (1955). Blindness in literature: examples of depictions and attitudes. New York: American Foundation for the Blind.

WELLS, Herbert G. (1911). The country of the blind. In: WELLS, H. G. The country of the blind and other stories. Nashville: Thomas Nelson and Sons. Disponível em: <http://www.online-literature.com/wellshg/3/>. Acesso em: 21 mai. 2008. 
Recebido em 29 de maio de 2017.

Aprovado em 17 de janeiro de 2018.

\section{resumo/abstract/re sumen}

\section{Turismo para cegos: velhos e novos simbolismos numa obra literária sobre a cegueira}

Manoela Cristina Correia Carvalho da Silva

Alessandra Santana Soares e Barros

Miralva dos Santos Silva

Turismo para Cegos, romance de estreia de Tércia Montenegro, é mais um texto que se junta à longa tradição de obras literárias que contam com a presença de personagens cegos. Neste artigo, retomamos os valores e crenças que alimentam a representação da cegueira na literatura ocidental, bem como apontamos os estereótipos mais comuns associados a personagens cegos em obras literárias, para analisarmos o romance em questão. Além disso, nos valemos da teoria de Erving Goffman acerca do estigma para estudar o intrincado teatro de relações estabelecido entre a protagonista cega e os demais personagens do romance. Concluímos que, apesar de retomar antigos estereótipos, Turismo para cegos também inova ao desmistificar a figura do estigmatizado, elevando-o ao status de um ser humano completo, tão passível de falhas quanto qualquer outro.

Palavras-chave: Tércia Montenegro, deficiência, literatura contemporânea, cegueira, estigma.

\section{Turismo para cegos: old and new symbolisms in a literary work on blindness}

Manoela Cristina Correia Carvalho da Silva

Alessandra Santana Soares e Barros

Miralva dos Santos Silva

Turismo para cegos, the debut novel by Tércia Montenegro, is yet another text that joins the long tradition of literary works that rely on the presence of blind characters. In this article, we revisit the values and beliefs that fuel the representation of blindness in Western literature, while also pinpointing some of the most common stereotypes associated with blind characters in literary works, in order to analyze the novel in question. In addition, we use Erving Goffman's theory of stigma to study the intricate theater of relationships established between the blind protagonist and the novel's other characters. We 
conclude that, despite perpetuating negative stereotypes, Turismo para cegos also innovates by demystifying the stigmatized figure, elevating it to the status of a complete human being, as faulty as any other.

Keywords: Tércia Montenegro, disability, contemporary literatura, blindness, stigma.

\section{Turismo para ciegos: viejos y nuevos simbolismos en una obra literaria sobre la ceguera}

Manoela Cristina Correia Carvalho da Silva

Alessandra Santana Soares e Barros

Miralva dos Santos Silva

Turismo para cegos, novela de estreno de Tercia Montenegro, es otro texto que se une a la larga tradición de obras literarias que cuentan con la presencia de personajes ciegos. En este artículo, retomamos los valores y creencias que alimentan la representación de la ceguera en la literatura occidental, así como resaltamos los estereotipos más comunes asociados a personajes ciegos en obras literarias, para analizar la novela en cuestión. Además, nos valemos de la teoría de Erving Goffman acerca del estigma para estudiar el intrincado teatro de relaciones establecido entre la protagonista ciega y los demás personajes de la novela. Concluimos que, a pesar de perpetuar antiguos estereotipos, Turismo para cegos también innova al desmitificar la figura del estigmatizado, elevándolo al estatus de un ser humano completo, tan susceptible de fallas como cualquier otro.

Palabras clave: Tércia Montenegro, deficiencia, literatura contemporánea, ceguera, estigma. 